\title{
O PAPEL DA FOSSILIZAÇÃO E DO INTEMPERISMO NA SISTEMÁTICA DE TRILOBITES PHACOPIDA (CALMONIIDAE E HOMALONOTIDAE) DO DEVONIANO DA BACIA DO PARANÁ, BRASIL
}

\author{
SABRINA PEREIRA SOARES \\ PG-Depto. Geologia Sedimentar e Ambiental, IG, USP, Rua do Lago, 562, 05508-900, São Paulo, SP. soares@igc.usp.br \\ MARCELLO GUIMARÃES SIMÕES \& JULIANA DE MORAES LEME \\ Depto.Zoologia, IB, UNESP, Rubião Júnior, Cx.P. 510, 18618-000, Botucatu, SP.btsimoes@ibb.unesp.br, leme@ibb.unesp.br
}

\begin{abstract}
RESUMO - Até o momento, aproximadamente 17 nomes específicos foram aplicados aos trilobites calmoniídeos da Formação Ponta Grossa, bacia do Paraná, sugerindo uma alta diversidade específica. A análise tafonômica de 516 espécimes de trilobites calmoniídeos $(n=412)$ e homalonotídeos $(n=104)$ da Formação Ponta Grossa revelou que algumas das espécies propostas não são, ao que tudo indica, válidas. Isso porque os caracteres morfológicos que as diagnosticam são o produto de alterações via processos de fossilização e intemperismo (pós-fossilização). Esse fato é particularmente evidente nos exemplares de "espécies" de trilobites preservados em diferentes litótipos (e.g., arenitos versus lamitos), com graus distintos de compactação e intemperismo. Para as espécies de calmoniídeos estudadas, três são os principais caracteres morfológicos susceptíveis a alterações, durante e após a fossilização: (i) forma e inflação do lobo glabelar, (ii) profundidade dos sulcos axiais e glabelares, e (iii) presença/ausência de ornamentação externa. Para os homalonotídeos, os seguintes caracteres morfológicos são susceptíveis de alteração: (i) forma do lobo glabelar, e (ii) presença/ausência de ornamentação externa. Com base no exposto acima, o status de algumas espécies de calmoniídeos (Paracalmonia paranaensis, P. cuspidata, Calmonia signifer, C. subseciva) e homalonotídeos (Burmeisteria herschelii e Digonus noticus) é discutido. Os dados apresentados reforçam a idéia de que a proposição de novas espécies de trilobites deva estar fundamentada em coleções numerosas, permitindo que o espectro de modificações tafonômicas, em diferentes litótipos seja detectado. Esse procedimento diminui o risco de estabelecimento de táxons com base em caracteres modificados pelos processos tafonômicos.
\end{abstract}

Palavras-chaves: Calmoniidae, Homalonotidae, tafotáxon, sistemática, Formação Ponta Grossa, bacia do Paraná.

\begin{abstract}
THE ROLE OF FOSSILIZATION AND WEATHERING IN THE SYSTEMATICS OF PHACOPIDA (CALMONIIDAE AND HOMALONOTIDAE) TRILOBITES, FROM THE DEVONIAN OF THE PARANÁ BASIN, BRAZIL. Until now, nearly 17 names were applied to the calmoniid trilobites of the Ponta Grossa Formation, Paraná Basin suggesting a high diversity Based on the taphonomic analysis of 516 specimens of calmoniid $(n=412)$ and homalonotid $(n=$ 104) trilobites it is now clear that some species are artificial, since the morphological features that diagnose them are the product of fossilization and weathering (post-fossilization). This is particularly true to those "species" that are preserved in different lithofacies, since they are submitted to distinct diagenetic (e.g., compression) and weathering (e.g., obliteration/ effacement) processes. To the studied calmoniid trilobites, three are the main morphological characters that are susceptible to modifications via taphonomy and weathering: (i) variation in inflation of glabelar lobe, (ii) variation in lobe shape, depth of axial and glabelar furrows, and (iii) presence/absence of external ornamentation. To the homalonotids, the following morphological characters are susceptible to modifications: (i) variation in glabelar lobe shape, and (ii) presence/absence of external ornamentation. Based on this, the status of some species of calmoniid (Paracalmonia paranaensis, P. cuspidata, Calmonia signifier, C. subseciva) and homalonotid (Burmeisteria herschelii and Digonus noticus) trilobites is discussed. Data presented here reinforces the idea that the erection of new trilobite species should be based on large scientific collections, enabling the detection of the patterns of morphologic variation both biologic and taphonomic. This procedure reduces the possibility to erect invalid taxa.
\end{abstract}

Key words: Calmoniidae, Homalonotidae, taphotaxon, systematics, Ponta Grossa Formation, Paraná Basin.

\section{INTRODUÇÃO}

Trilobites, juntamente com os braquiópodes e conulários estão dentre os invertebrados marinhos do Devoniano do Paraná cuja tafonomia é relativamente bem conhecida (Simões et al., 2000a, b, 2003; Rodrigues et al., 2003; Bosetti, 2004; Ghilardi, 2004; Ghilardi \& Simões, 2007;
Zabini, 2007). No caso específico dos trilobites, o modo como os processos bioestratinômicos e diagenéticos atuam na preservação dos escleritos foi, em parte, estudado por Ghilardi (2004). Esse autor constatou que os trilobites da Formação Ponta Grossa estão tipicamente preservados em dois modos distintos: (i) trilobites articulados, onde todos os segmentos do corpo estão associados e; (ii) trilobites desarticulados, 
onde ao menos um dos escleritos corpóreos está dissociado do restante.

Em razão das condições deposicionais da Formação Ponta Grossa, as carapaças dos trilobites não estiveram sujeitas a intenso retrabalhamento ou transporte hidráulico. De fato, concentrações densas de trilobites, à moda de coquinas, como as descritas por Speyer \& Brett (1986) e Speyer (1987), para as rochas devonianas do Grupo Hamilton de Nova York, por exemplo, não estão presentes no Devoniano da bacia do Paraná. Contrariamente, os restos de trilobites ocorrem tipicamente desarticulados e dispersos na matriz sedimentar, preservados em diferentes atitudes, com relação ao plano de acamadamento. Em muitos casos, existem evidências (e.g., bioturbação) de que a atitude original das carapaças foi modificada pela intensa atividade biológica intraestratal (vide Simões et al., 2000a e Rodrigues et al., 2003, para exemplo similar com Conulata).

Soares (2007) notou, com base na distribuição vertical dos trilobites da Formação Ponta Grossa, que esses fósseis ocorrem, preferencialmente, em três tafofácies distintas, representativas de um gradiente batimétrico de águas rasas (acima do nível de base de ondas de tempo-bom, Tafofácies TII) a relativamente profundas (abaixo do nível de base de ondas de tempestades, Tafofácies TIII e TIV). As condições deposicionais mais energéticas são notadas nas assembléias representativas da Tafofácies TII (Soares, 2007), onde os trilobites estão preservados em arenitos finos a siltitos, da base da Formação Ponta Grossa (Bosetti, 2004). Já nas Tafofácies TIII e TIV, predominam os espécimes preservados dispersos na matriz sedimentar, em geral, siltitos a arenitos finos, às vezes com intensa bioturbação e estratificação cruzada do tipo micro-hummocky (Tafofácies TIII) e argilitos escuros, maciços (Tafofácies TIV), depositados abaixo do nível de base de ondas de tempestades. No esquema de Soares (2007), trilobites não são registrados nas Tafofácies I e V do modelo de Speyer \& Brett (1986) e Sandford (2005), equivalentes, respectivamente, a ambientes de águas extremamente rasas ou profundas.

A análise de dados publicados em estudos prévios (Clarke, 1913; Kozlowski, 1923; Reed, 1925; Eldredge \& Branisa, 1980; Cooper, 1982; Popp, 1985; Carvalho \& Quadros, 1987; Edgecombe, 1990) e das numerosas coleções de trilobites disponíveis para estudo no Brasil, pertencentes à Universidade Estadual Paulista, Campus de Botucatu (IBB/ UNESP), da Universidade Estadual de Ponta Grossa (UEPG), da Universidade Guarulhos (UNG), da Universidade de São Paulo (USP) e da Universidade Federal do Paraná (UFPR), evidenciou que determinados processos tafonômicos (compactação) e intempéricos (esfoliação), podem levar a alterações morfológicas importantes, tanto na carapaça de espécies de calmoniídeos, como de homalonotídeos. Inadvertidamente, tais modificações podem conduzir a interpretações taxonômicas equivocadas. Esse fato tem importantes reflexos na determinação da afinidade, da diversidade, da abundância e do significado paleobiogeográfico das faunas de trilobites Phacopida da Formação Ponta Grossa, um dos grupos fósseis mais abundantes dessa unidade litoestratigráfica. Em especial, a coleção do Laboratório de Paleozoologia Evolutiva, do IBB/ UNESP, contém diversos exemplares de calmoniídeos e homalonotídeos da Formação Ponta Grossa cuja distribuição faciológica e posicionamente estratigráfico são bem conhecidos. Exemplares de espécies provenientes de arenitos finos e folhelhos mostram, por exemplo, variação no grau de compressão de algumas estruturas morfológicas (e.g., glabela) o que poderia levar a descrições e interpretações taxonômicas equivocadas. Esse fato motivou a elaboração do presente estudo, que tem por objetivos: (i) destacar o papel do processo de fossilização e intemperismo (pós-fossilização) na modificação de feições morfológicas em espécies de trilobites calmoniídeos e homalonotídeos da Formação Ponta Grossa e (ii) avaliar o impacto dos dados obtidos na sistemática da fauna de trilobites aqui estudados.

\section{MATERIAL EXAMINADO E PROCEDÊNCIA}

Os espécimes analisados pertencem à Coleção Científica do Labroratório de Paleozoologia Evolutiva do Instituto de Biociências da UNESP, Campus de Botucatu e são provenientes da Formação Ponta Grossa, Membro Jaguariaíva (Petri, 1948; Lange \& Petri, 1967; Petri, 2006) ou Seqüência B (Bergamaschi, 1999; Bergamaschi \& Pereira, 2001). No total, 516 espécimes de trilobites Phacopida, incluindo 104 exemplares de homalonotídeos e 412 exemplares de calmoniídeos foram analisados. Esses espécimes foram coletados em afloramentos localizados nos municípios de Ponta Grossa, Tibagi e Jaguariaíva, Estado do Paraná (Figura 1).

Os afloramentos de Jaguariaíva, de onde provém a maioria dos exemplares coletados, localizam-se nos quilômetros $2,2 \mathrm{e}$ 6,0 do corte da estrada de ferro Jaguariaíva-Arapoti, abrangendo o intervalo estratigráfico entre 17 a $48 \mathrm{~m}$ da base da seção (Figura 2A). Esse intervalo estratigráfico é caracterizado pela ocorrência de depósitos de sufocamento (Simões et al., 2000a, b; Rodrigues et al., 2003), os quais são progressivamente sucedidos por folhelho cinza escuro laminado e siltitos e arenitos interlaminados, com intensa bioturbação (Bergamaschi \& Pereira, 2001). Esses folhelhos representariam eventos de inundação marinha (Bergamaschi \& Pereira, 2001).

No município de Tibagi, os espécimes foram coletados ao longo da seção aflorante na PR-340, entre os municípios de Castro e Tibagi, e na estrada de ligação entre Tibagi e Telêmaco Borba (Bergamaschi, 1999; Bosetti, 2004; Ghilardi, 2004). As coletas na PR-340 foram realizadas no quilômetro 60, correspondente ao intervalo basal da Formação Ponta Grossa. Sua constituição é de arenito fino com estratificação de baixo ângulo, siltitos cinza-médios, micáceos, fossilíferos, representando depósitos litorâneos de foreshore e shoreface (Bergamaschi \& Pereira, 2001) (Figura 2B). Com relação ao afloramento da estrada Tibagi-Telêmaco Borba, as coletas foram efetuadas nas proximidades da cidade de Tibagi (cerca de $3 \mathrm{~km}$ rumo NW), referente ao intervalo de 27 a $70 \mathrm{~m}$ da base da seção. Nesse afloramento predominam folhelhos ou siltitos 


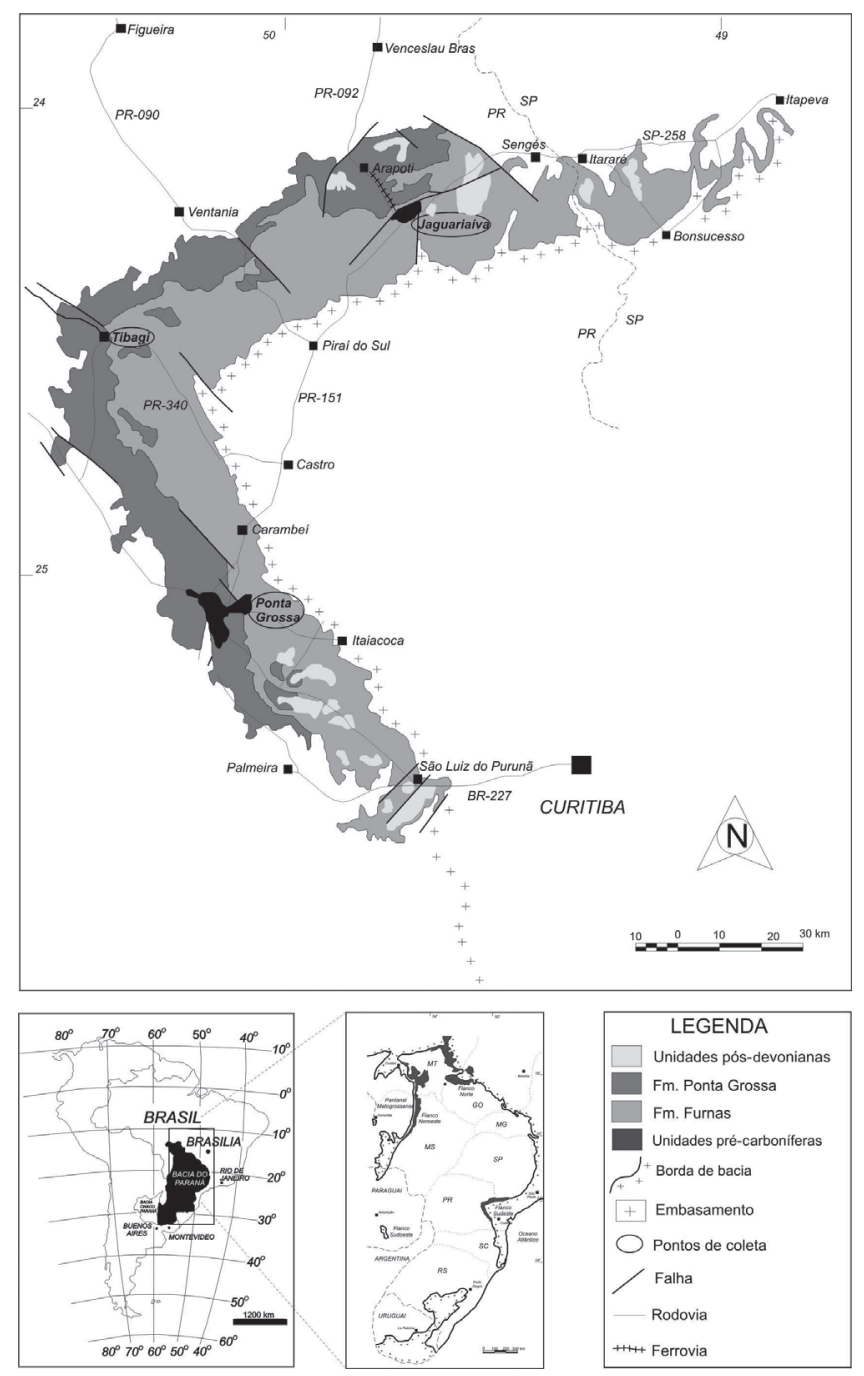

Figura 1. Mapa de localização dos afloramentos estudados da Formação Ponta Grossa, mostrando a faixa de afloramentos na borda leste da bacia do Paraná.

Figure 1. Location map of the studied outcrops of the Ponta Grossa Formation, showing the outcrop belt in the eastern margin of Paraná Basin.

cinza-médio a escuro, laminados a bioturbados, que gradam para siltitos com interlaminações delgadas de arenito muito fino. Para o topo, há o aparecimento de estratos de arenitos muito fino e fino, com estratificação cruzada tipo hummocky (Bergamaschi \& Pereira, 2001) (Figura 2B).

As coletas realizadas em Ponta Grossa foram conduzidas no afloramento denominado Vila Francelina (Bosetti, 2004) ou Francelina 01 de Myszynski \& Bosetti (2006). Esse afloramento é constituído por $2 \mathrm{~m}$ de siltitos maciços, com intercalações de lentes de arenito muito fino (Figura 2C), com ocorrência freqüente de nódulos ferruginosos e concreções contendo fósseis muito bem preservados. Esse pacote é altamente fossilífero, em especial, em restos de trilobites e seria correlacionável ao topo da seção estratigráfica da Formação Ponta Grossa aflorante no câmpus da Universidade Estadual de Ponta Grossa (Myszynski \& Bosetti, 2006).

Em síntese, os fósseis de trilobites examinados provêm de diferentes estratos da porção basal-média da Formação Ponta Grossa, contendo macrofósseis marinhos que materializam distintas fácies tafonômicas (vide Rodrigues et al., 2003).

\section{MARCO CONCEITUAL}

\section{Definindo o problema: tafonomia e sistemática de trilobites}

Trilobites estão entre os invertebrados fósseis cujo processo de preservação é muito bem conhecido. Desde os estudos de Hesselbo (1987), Speyer $(1987,1988)$ e Speyer \& Brett $(1985,1986)$, paralelamente aos de Brett \& Baird (1986), Westrop (1986), Babcock \& Speyer (1987), até estudos mais recentes (Hunda et al., 2006), ficou evidenciado o potencial dos restos esqueletais dos trilobites como indicadores da dinâmica sedimentar e da história deposicional dos estratos portadores desses fósseis. Entretanto, a despeito do enorme conhecimento acumulado sobre a bioestratinomia das carapaças dos trilobites, pouco se sabe sobre os efeitos da tafonomia na taxonomia do grupo (vide Hughes, 1995). Porém, alguns autores, como Kiaer (1917), Henningsmoen (1957) e Fortey (1974), estudaram detidamente a questão de como a compactação afeta a morfologia dos escleritos dos trilobites preservados em litótipos finos, por exemplo. Outros autores, tais como Taylor (1978) e Jell (1985), respectivamente, investigaram as diferenças na preservação de espécimes de trilobites contidos em rochas carbonáticas e siliciclásticas e, entre moldes internos e externos.

Hughes $(1993,1995)$ se destaca como um dos poucos estudiosos da sistemática dos trilobites a se preocupar com os efeitos da tafonomia na sistemática do grupo, tendo investigado essa questão em nível de espécie. O autor utilizou como exemplo o táxon Bailiella lantenoisi (Conocoryphidae) do Cambriano médio. Hughes (1995) notou que, dos 38 caracteres morfológicos identificados (23 para o céfalo, cinco para o tórax, 10 para o pigídio), somente 14 aparentemente não sofreram modificação via processos tafonômicos. Dos 23 caracteres listados para o céfalo de Bailiella lantenoisi, por exemplo, 15 são passíveis de alteração via obliteração/ compressão, quando preservados em folhelhos. Do total de 38 caracteres, 18 só podem ser reconhecidos em exemplares preservados em rochas carbonáticas. Esses dados apontam para o cuidado que os sistematas de trilobites devem ter quanto à qualidade de preservação do material antes da proposição de novos táxons (vide discussão mais abaixo), especialmente quando o táxon ocorre em rochas carbonáticas e siliciclásticas.

\section{Processos tafonômicos e variação morfológica}

Lucas (2001) introduziu, na literatura paleontológica, o termo "tafotáxon", em alusão aos táxons erigidos com base em caracteres morfológicos que são fruto de alterações produzidas pelo processo de fossilização, maiormente a diagênese. Tais táxons são obviamente inválidos. Embora o termo tafotáxon seja novo, no que tange à paleontologia de macro-invertebrados, a questão da identificação de caracteres morfológicos que têm origem realmente biológica daqueles 


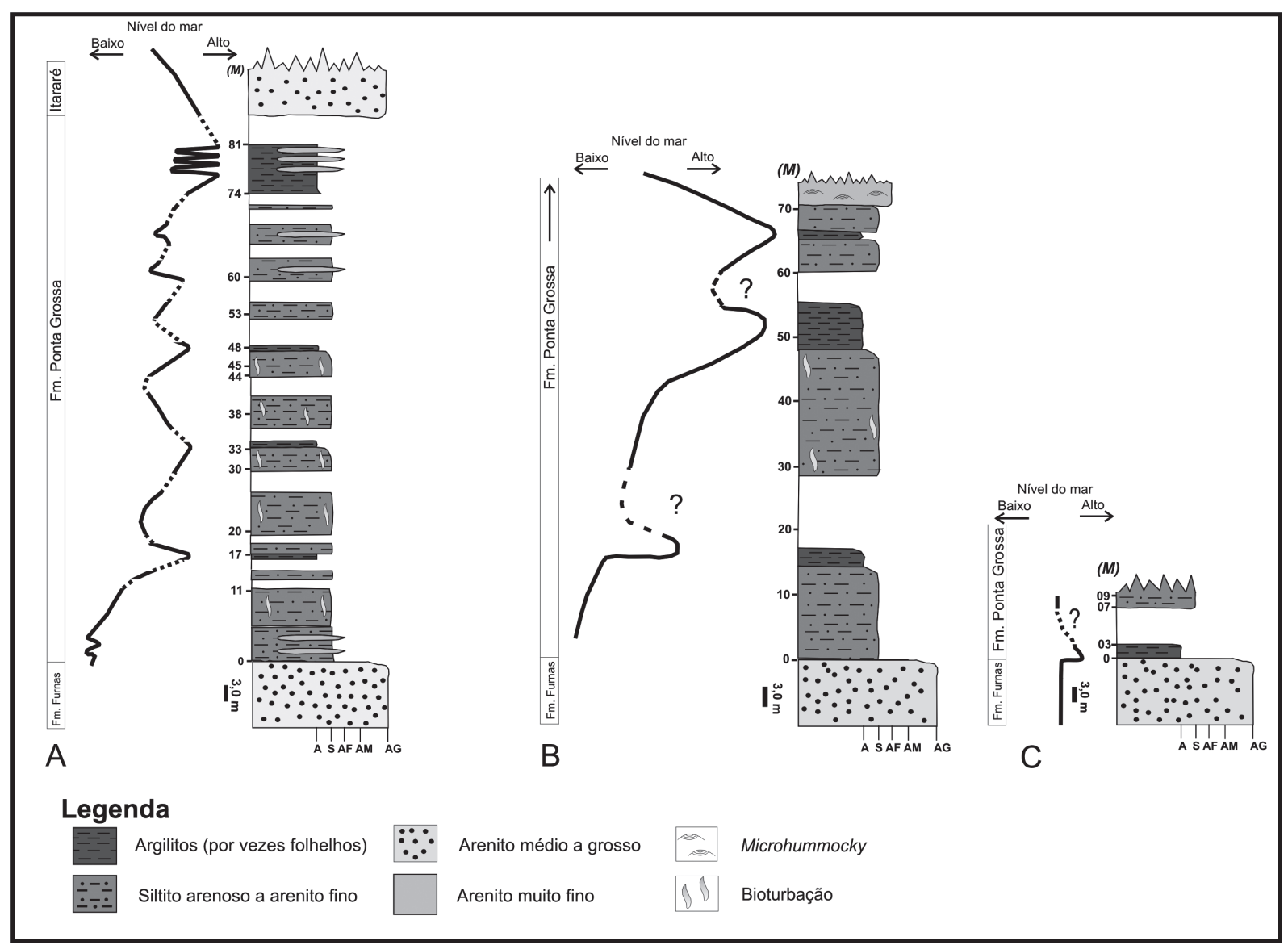

Figura 2. Seções colunares dos afloramentos da Formação Ponta Grossa (=Membro Jaguariaíva); A, seção colunar de Jaguariaíva, ao longo do ramal ferroviário; B, seção composta da formação incluindo os litotipos aflorantes ao longo da PR-340, na entrada de Tibagi (PR), bem como da estrada Tibagi-Telêmaco Borba; C, seção colunar de Ponta Grossa, Vila Francelina (modificado de Ghilardi, 2004 e Bosetti, 2004).

Figure 2. Columnar sections of the Ponta Grossa Formation (=Jaguariaíva Member); A, columnar section at the Jaguariaíva-Arapoti railroad, Jaguariaíva County; $\mathbf{B}$, composed section of the formation including the lithotypes cropping out in the PR-340 highway, Tibagi County and those exposed in the Tibagi-Telêmaco Borba road; C, section of the rocks at the Vila Francelina outcrop, Ponta Grossa County (sections modified from Ghilardi, 2004 and Bosetti, 2004).

que são resultantes do processo de fossilização há muito preocupa os paleontólogos. Apenas para citar exemplos brasileiros, Rocha-Campos (1970) demonstrou que a diversidade da fauna marinha de Taió (Formação Rio Bonito, Permiano Inferior, bacia do Paraná, Estado de Santa Catarina) era menor, do que a suposta anteriormente por Reed (1930) e Kegel \& Costa (1951). Isso porque, Rocha-Campos (1970) constatou que as sete espécies de pectinídeos atribuídas ao gênero Heteropecten (=Aviculopecten) eram variantes intraespecíficas de Aviculopecten catharinae, sendo que as alterações na ornamentação das valvas eram fruto, em geral, do processo de fossilização (moldes compostos, vide RochaCampos, 1966).

Outro exemplo com fósseis brasileiros é o estudo de Holz \& Schultz (1998) sobre a influência da diagênese na morfologia de cinodontes triássicos da Formação Santa Maria, no Rio Grande do Sul. Esses autores demonstraram que, durante a fase eodiagenética, houve permineralização dos ossos, seguida da ação deslocadora de carbonato de cálcio (calcita). A recristalização desses minerais conduz à expansão da estrutura óssea, levando a um aumento de volume da ordem de $100 \%$. Essas alterações diagenéticas levaram a modificações morfológicas que conduziram a interpretações taxonômicas errôneas. Nesse caso, algumas espécies e gêneros foram estabelecidos com base nas alterações produzidas pela diagênese (Holz \& Schultz, 1998).

Mais recentemente, Simões et al. (2003) estudaram detalhadamente a tafonomia dos conulários (Cnidária) da Formação Ponta Grossa (Devoniano, Estado do Paraná), tendo demonstrado que esse grupo fóssil em particular constitui importante exemplo de como os caracteres biométricos, dentre outros, utilizados na diagnose de gêneros e espécies de Conulata são afetados ou modificados pela fossilização. Tal condição leva à proposição de táxons inválidos ou artificiais (Simões et al., 2003).

Um aspecto comum a todos os estudos acima, que ressaltaram o papel da fossilização na alteração de caracteres morfológicos, é o de que os autores fundamentaram suas observações em coleções numerosas. Nesses casos, conseqüentemente, o espectro de variações ou modificações morfológicas dos caracteres diagnósticos fica mais evidente, especialmente quando os exemplares vêm de intervalos 
estratigráficos distintos e, portanto, às vezes, com histórias tafonômicas diferentes. Nesse contexto, Macnaughton \& Pickerill (2003) introduziram o termo "tafosérie", para designar séries de exemplares fósseis representando a perda ou alteração de feições morfológicas de um mesmo táxon, em especial, no caso desses autores, de icnofósseis.

Na realidade, as observações de Macnaughton \& Pickerill (2003) estão de acordo com as sugestões de Simões et al. (2003), segundo as quais a descrição de novas espécies na paleontologia de macro-invertebrados deveria fundamentarse em coleções numerosas, possibilitando a identificação do maior espectro possível de variações morfológicas, decorrentes de alterações tafonômicas. Isso evitaria a validação de táxons artificiais, o que causa uma falsa idéia de diversidade da fauna, com importantes implicações paleoecológicas e sistemáticas.

\section{RESULTADOS}

\section{Fatores tafonômicos que afetam a preservação dos trilobites do Devoniano da bacia do Paraná}

Aparentemente, os principais fatores que afetam a morfologia dos escleritos dos trilobites estudados não estão associados à fase bioestratinômica da fossilização (vide Fernández Lopez, 2000 e Holz \& Simões, 2001, para as etapas da fossilização), já que, com uma possível exceção, ou seja, dos restos preservados em arenitos finos, representativos da Tafofácies TII (Soares, 2007), são raros os escleritos submetidos a intenso retrabalhamento. Porém, a diagênese e o intemperismo são os fatores mais importantes na alteração da morfologia dos escleritos dos trilobites estudados. Esses fatores atuam em intensidades distintas, dependendo da tafofácies considerada e a condição de exposição ao intemperismo das rochas dos afloramentos investigados.

Processos de alteração durante a fossilização (diagênese). Trilobites provenientes de siltitos, por vezes intensamente bioturbados, da parte média da Formação Ponta Grossa (equivalentes a Tafofácies TIII de Soares, 2007) estão preservados concordantemente ou oblíquos ao plano de acamadamento. Essa atitude (carapaças oblíquas ao plano) é resultante da atividade biológica intraestratal, que modifica o arranjo tridimensional das carapaças na matriz sedimentar (vide Rodrigues et al., 2003, para exemplo semelhante com conulários). Compressão devido à compactação mecânica, especialmente durante a eodiagênese, causa deformação diferencial dos restos de trilobites preservados concordamente ou obliquamente ao plano de acamadamento. A compactação dos restos de trilobites jazendo concordantemente ao plano de acamadamento produz achatamento dorso-ventral da carapaça. Porém, nas formas cujo exoesqueleto está preservado de maneira oblíqua ao plano de acamadamento, o achatamento produzido será lateral à carapaça. Além disso, não raro, os fósseis de trilobites da Formação Ponta Grossa podem apresentar preservação das carapaças de maneira torcida (=não estendida; vide Ghilardi, 2004). Assim sendo, o sentido de achatamento produzido pela compactação poderá ser distinto ao longo do eixo de uma mesma carapaça. Em outras palavras, restos de trilobites, de um mesmo táxon, encontrados em estratos distintos (arenito versus argilito), com histórias diagenéticas diferentes, poderão apresentar graus de achatamento distintos, o que leva a modificações de caracteres biométricos considerados diagnósticos.

Processos de alteração após a fossilização (intemperismo). Em todas as ocorrências investigadas, a obliteração da carapaça por esfoliação, com tendência ao "apagamento" (effacement) ou perda das estruturas proeminentes é o processo intempérico que ocorre com maior freqüência nos trilobites examinados (vide Simões et al., 2003, para exemplos semelhantes com conulários). As rochas das três localidades investigadas, nos Campos Gerias do Paraná, isto é, de Jaguariaíva, Tibagi e Ponta Grossa, estão submetidas a duas condições climáticas distintas, porém úmidas. Segundo a classificação de W. Köppen (IAPAR, 2000; Maack, 2002; Cruz, 2007), na área de estudo o clima pode ser classificado como do tipo $\mathrm{Cfa}$ - clima subtropical úmido quente (município de Tibagi) - e do tipo $\mathrm{Cfb}$ - clima temperado sempre úmido (municípios de Jaguariaíva e Ponta Grossa). Na área dos afloramentos investigados, a precipitação média anual gira em torno de $1.400 \mathrm{~mm}$ a $1.800 \mathrm{~mm}$ (Cruz, 2007). Conseqüentemente, há ampla disponibilidade de água no sistema natural.

A percolação de água meteórica, junto aos estratos fossilíferos, em especial os expostos junto à superfície dos afloramentos, causa intenso intemperismo. Em decorrência desse fenômeno pós-fossilização, há modificação de certas feições morfológicas, com obliteração via esfoliação da rocha e dos fósseis. Esse processo é particularmente severo nas carapaças de trilobites preservadas em arenitos finos a siltitos da Tafofácies TII, na porção basal da Formação Ponta Grossa. O mais belo exemplo conhecido desta condição é mostrado pelos fósseis provenientes do afloramento Vila Francelina (ou Francelina 01), no município de Ponta Grossa (Bosetti, 2004; Myszynski \& Bosetti, 2006). Tal fato não é surpresa, pois as maiores médias pluviométricas anuais constatadas nos Campos Gerais (1.600 a $1.800 \mathrm{~mm}$ ) ocorrem justamente na área do município de Ponta Grossa (Cruz, 2007). Uma vez que os arenitos finos a siltitos da Tafofácies TII são mais permeáveis, do que os argilitos maciços da Tafofácies TIV, na parte média/superior da Formação Ponta Grossa, a percolação de água meteórica é intensa nesse litotipo. Portanto, o intemperismo é extensivo nos estratos arenosos, levando à decomposição da rocha e à esfoliação dos fósseis. Trilobites provenientes da Tafofácies TII estão intensamente esfoliados, às vezes, com perda total ou obliteração das estruturas elevadas/rebaixadas da carapaça, bem como da ornamentação (vide discussão mais adiante).

\section{Caracteres morfológicos passíveis de modificação via tafonomia e intemperismo}

Forma, grau de inflação da glabela e direção do lobo glabelar. Nos Calmoniidae, as feições (i) forma, (ii) grau de inflação da glabela e (iii) dos lobos glabelares, são alguns dos caracteres diagnósticos utilizados na determinação de 
gênero (Clarke, 1913; Kozlowski, 1923; Harrington et al., 1959; Eldredge \& Branisa, 1980; Cooper, 1982; Popp, 1985; Carvalho \& Edgecombe, 1991; Lieberman et al., 1991; Lieberman, 1993; Popp et al., 1996; Carvalho et al., 1997). Já em Homalonotidae, dentre essas feições (forma, grau de inflação da glabela e do lobo glabelar), somente a forma da glabela é feição utilizada para diagnose genérica (Lake, 1904; Reed, 1918, 1925; Clarke, 1913; Kozlowski, 1923; Gill, 1948; Harrington et al., 1959; Pillet, 1961; Saul, 1965, 1967; Tomczykowa, 1975; Baldis et al., 1976; Thomas, 1977; Chlupác, 1981; Henry, 1981; Arbizu, 1982; Cooper, 1982; Busch \& Swarz, 1985; Wenndorf, 1990; Sandford, 2005; Carvalho, 2006).

A compressão (via compactação) e a obliteração (via intemperismo) podem modificar os caracteres acima, com impacto nos dados biométricos colhidos (veja também Henningsmoen, 1957). Por exemplo, a compactação altera a direção e o comprimento dos sulcos laterais glabelares e do sulco axial. Essa condição é evidente nos exemplares de Calmonia signifer, representados pelos espécimes DZP17413 e DZP-17190 (Figuras 3A, B), que foram coletados em argilitos da Tafofácies TIV de Jaguariaíva. De fato, ao se comparar o exemplar DZP-17651b (Figura 3H), proveniente de arenitos e siltitos da Tafofácies TII, com os provenientes de argilitos das Tafofácies TIII e TIV (Figuras 3A, B) é possível notar que o grau de achatamento desses exemplares é distinto. Nesses casos, o grau de inflação do lobo glabelar é variável dentro de exemplares de um mesmo táxon. Esse exemplo pode ser claramente observado nos espécimes DZP18419 e DZP-17187a. Conforme mostrado na Figura 4E, o espécime compactado (DZP-18419) apresenta o lobo glabelar achatado e não inflado, enquanto que o exemplar DZP-17187a, não achatado, possui lobo glabelar inflado (Figura 3D).

Por outro lado, os espécimes de Homalonotidae encontrados na sub-bacia Apucarana podem pertencer a duas espécies, Burmesiteria herschelii e Digonus noticus, de acordo com Soares (2007). Umas das feições que as diferem é a forma da glabela, sendo a glabela de $B$. herschelii urceolada, e a de $D$. noticus trapezoidal. Entretanto, ao observar os exemplares DZP-3391c (Figura 4A), correspondente a $B$. herschelii, e DZP-17667, D. noticus (Figura 4B), nota-se que a forma da glabela pode ser modificada pela compactação dos espécimes, alterando, por vezes, a forma urceolada para trapezoidal (Figura 4A). Portanto, nesses casos, a identificação taxonômica específica poderá ficar comprometida.

Profundidade do axis e sulcos glabelares. Em Calmoniidae, os sulcos laterais glabelares e o sulco axial variam em profundidade (Clarke, 1913; Kozlowski, 1923; Harrington et al., 1959; Eldredge \& Branisa, 1980; Cooper, 1982; Popp, 1985; Carvalho \& Edgecombe, 1991; Lieberman et al., 1991; Lieberman, 1993; Popp et al., 1996; Carvalho et al., 1997). A esfoliação da carapaça conduz ao "apagamento" (effacement) dessa estrutura. A Figura 3 mostra dois exemplares de $C$. signifer representados por céfalos em diferentes estágios de preservação. O espécime DZP-17167 (Figura 3F), proveniente de argilito da Tafofácies TIV, município de Jaguariaíva, está parcialmente esfoliado. Note que nesse exemplar, os sulcos glabelares L2 e L3 estão praticamente ausentes (ou apagados), conferindo à glabela um aspecto quase liso. Por sua vez, o espécime DZP-18324 (Figura 3G), também proveniente de argilito (Tafofácies TIV) está mais bem preservado, isto é, com baixo grau de esfoliação. Nele, os sulcos glabelares (L1, L2, L3) são profundos e estão bem marcados. Já o espécime DZP-17413 (Figura 3A) encontrado nos mesmos litotipos acima, apresenta uma condição de preservação, por assim dizer, intermediária entre a mostrada pelos espécimes 17167 e 18324 (Figuras 3F e G, respectivamente). Nesse caso, os sulcos glabelares (L1, L2, L3) são claramente visíveis, mas são rasos. Presença/ausência da ornamentação. A presença/ausência de ornamentação da carapaça é outra feição morfológica utilizada na diagnose genérica e específica de membros das famílias Calmoniidae e Homalonotidae. Em Calmoniidae a ornamentação é representada por (i) espinhos ou tubérculos que ocorrem nos ângulos genais, (ii) tubérculos nas glabelas, (iii) lapelas na pleura pigidial, (iv) espinho terminal e espinhos na margem pigidial (Clarke, 1913; Kozlowski, 1923; Harrington et al., 1959; Eldredge \& Branisa, 1980; Cooper, 1982; Popp, 1985; Carvalho \& Edgecombe, 1991; Lieberman et al., 1991; Lieberman, 1993; Popp et al., 1996; Carvalho et al., 1997). Já em Homalonotidae, a ornamentação é representada pela (i) presença de nódulos por toda a superfície dos céfalos e pigídios e, (ii) tubérculos ao longo do axis pigidial (Tomczykowa, 1975; Baldis et al., 1976; Chlupác, 1981; Wenndorf, 1990; Sandford, 2005; Carvalho, 2006).

A presença/ausência ou mesmo o grau de definição das estruturas acima mencionadas varia muito, com relação à intensidade da esfoliação da carapaça dos exemplares da Formação Ponta Grossa. Os espécimes (DZP-17413, DZP17190; Figura 3A, B) representam exemplares intemperizados de $C$. signifer onde os tubérculos foram parcialmente perdidos por esfoliação. Nesse caso, a carapaça tende a apresentar um aspecto quase liso sugerindo ausência dos turbérculos.

Ainda em Calmoniidae, a presença/ausência de espínulos nos ângulos genais é uma feição diagnóstica da espécie $C$. signifer. Nas coleções examinadas, os espécimes DZP-2234a, DZP-17167, DZP-17190, DZP-17413, DZP-18324 (Figura 3) apresentam a maioria das feições diagnósticas dessa espécie, ou seja, (i) céfalo subtriangular, (ii) margem anterior cefálica com processo frontal mediano, (iii) espinho genal pequeno, (iv) pigídio micropigio, subtriangular e (v) bordo pigidial com seis pares de espinhos dirigidos posteriormente, com espinho posterior terminal. Notavelmente, porém, em apenas em um deles é possível observar a presença de espínulos nos ângulos genais (Figura 3B). Essa condição é raramente observada nos espécimes paranaenses, pois os ângulos genais, quando presentes, estão esfoliados, obliterando a preservação dos espínulos (Figura 3A, C, F, G).

Já em Homalonotidae, a espécie Digonus noticus apresenta como uma das feições diagnósticas a presença de nódulos distribuídos por toda superfície do céfalo. No entanto, conforme observado no exemplar DZP-17667 (Figura 4B), proveniente de arenitos (Tafofácies TII), essa feição pode estar ausente devido à esfoliação da carapaça. $\mathrm{O}$ mesmo ocorre com o pigídio dessa espécie, como observado nos espécimes DZP-17650a, DZP-17638a e DZP-17679 (Figuras 


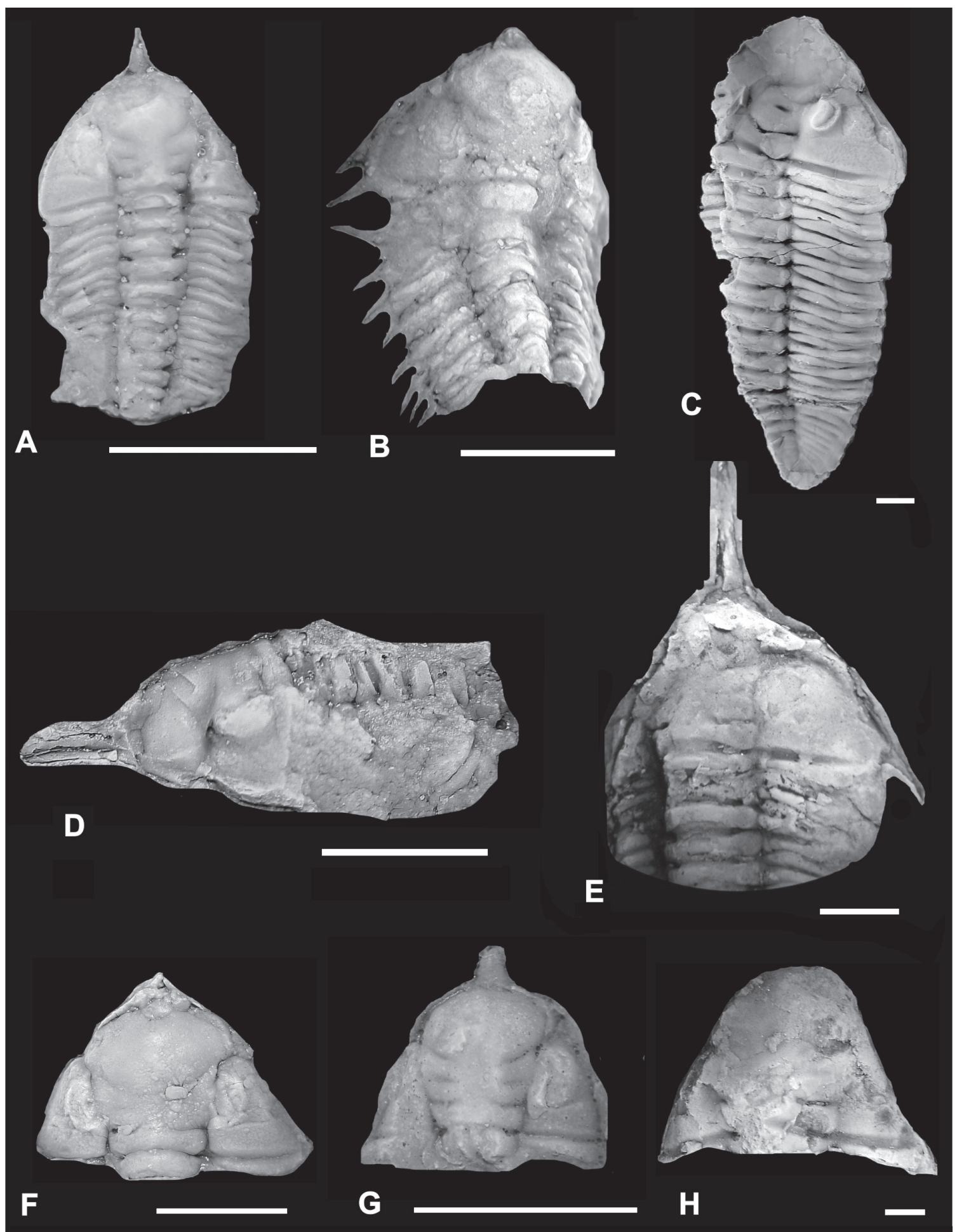

Figura 3. Calmonia signifer (A-C, F-H) e Paracalmonia cuspidata (D-E): A, céfalo-tórax com sulcos glabelares (L1, L2, L3) visíveis, rasos, tubérculos parcialmente perdidos (DZP-17413); B, céfalo-tórax com espínulos nos ângulos genais (DZP-17190); C, espécime estendido, com tubérculos parcialmente perdidos (DZP-2234a); D, céfalo-tórax com lobo glabelar inflado (DZP-17187a); E, céfalo-tórax esfoliado, lobo glabelar achatado (DZP-18419); F, céfalo parcialmente esfoliado, sulcos glabelares L2 e L3 ausentes (ou apagados) (DZP17167); G, céfalo com baixo grau de esfoliação, sulcos glabelares (L1, L2, L3) profundos e bem marcados (DZP-18324); H, céfalo esfoliado e achatado (DZP-17651b). Escalas $=5 \mathrm{~mm}$.

Figure 3. Calmonia signifer (A-C, F-H) and Paracalmonia cuspidata (D-E): A, cephalonthorax with shallow glabelar furrows (L1, L2, L3) and partially absent tubercles (DZP-17413); B, cephalon-thorax showing genal angles with spinules (DZP-17190); C, outstretched specimen with partially lost tubercles (DZP-2234a); D, cephalon-thorax with inflated glabelar lobe (DZP-17187a); E, exfoliated cephalonthorax with flattened glabelar lobe (DZP-18419); F, partially exfoliated cephalon, glabelar furrows L2 and L3 absent (or effacement) (DZP17167); G, partially exfoliated cephalon, deep and well marked glabelar furrows (L1, L2, L3) (DZP-18324); H, exfoliated and flattened cephalon (DZP-17651b). Scale bars $=5 \mathrm{~mm}$. 


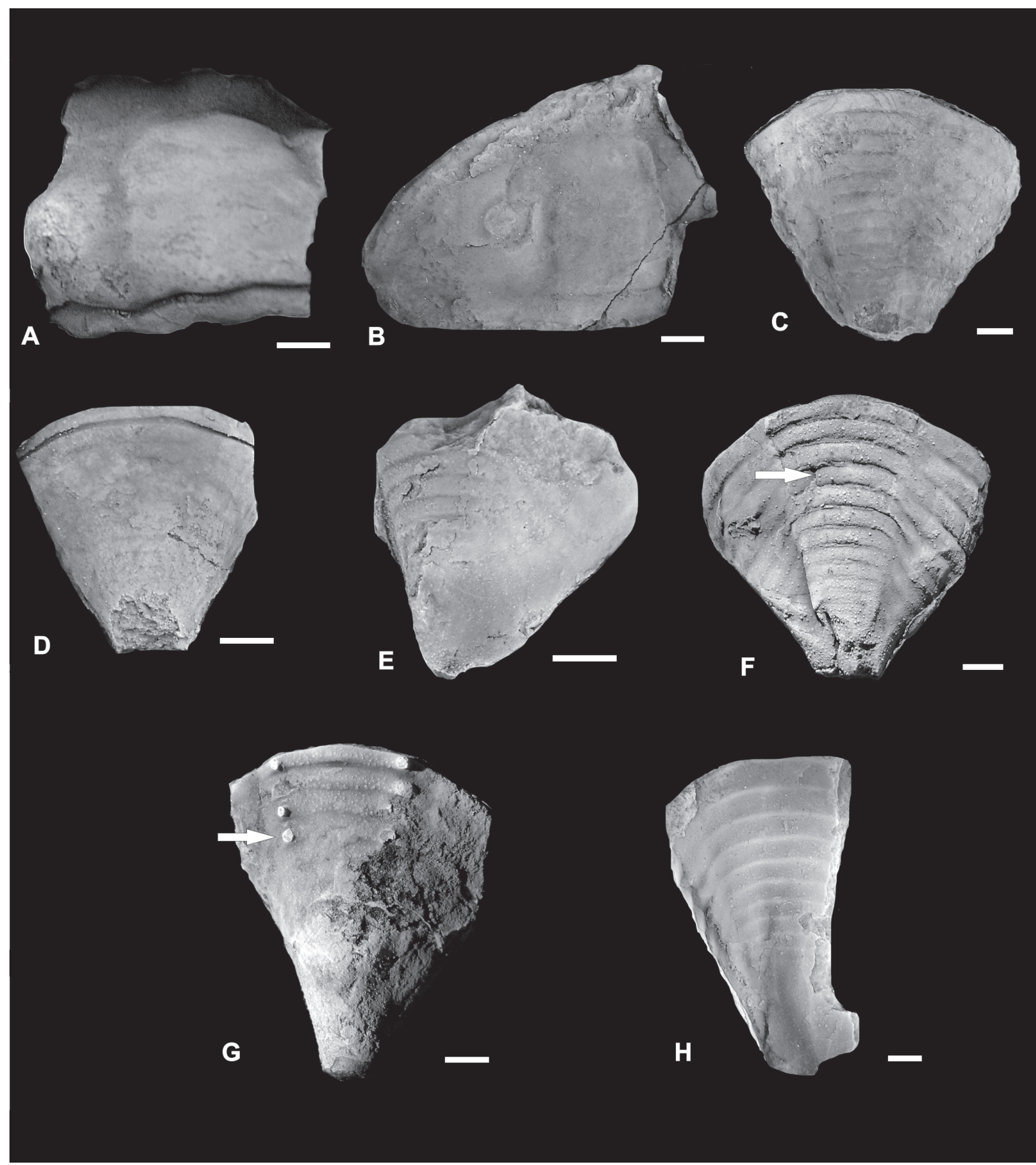

Figura 4. Burmeisteria herschelii (A, G, H) e Digonus noticus (B-F): A, céfalo com glabela compactada, alterando a forma de urceolada para trapezoidal (DZP-3391c); B, céfalo com glabela trapezoidal, não compactada, ausência de nódulos na carapaça (DZP-17667); C-E, pigídio esfoliado, nódulos ausentes (DZP-17650a, DZP-17638a, DZP-17679); F, pigídio com nódulos preservados (seta) (DZP-3367a); G, pigídio com tubérculos no axis pigidial (DZP-2247b); H, pigídio esfoliado, tubérculos ausentes (DZP-17648b). Escala $=5 \mathrm{~mm}$.

Figure 4. Burmeisteria herschelii (A, G, H) and Digonus noticus (B-F): A, cephalon with compressed glabella, changing the glabelar shape from urceolate to trapezoidal (DZP-3391c); B, cephalon showing the uncompressed trapezoidal glabella, nodules absent (DZP17667); C-E, exfoliated pygidium, without granules (DZP-17650a, DZP-17638a, DZP-17679); F, pygidium with preserved granules (arrow) (DZP-3367a); G, pygidium with tubercles along to the axial furrows (DZP-2247b); H, exfoliated pygidium, tubercles absent (DZP-17648b). Scale bar $=5 \mathrm{~mm}$. 
4C-E), dos mesmos arenitos, onde os nódulos não estão presentes, fornecendo a falsa impressão de que esse exemplar possui a carapaça lisa. Notavelmente, em DZP-3367a (Figura 4F), preservado em siltito (Tafofácies TIII), os nódulos estão preservados no pigídio. Em Burmeisteria herschelii, a presença de tubérculos ao longo do axis pigidial (DZP-2247b, Figura 4G), é a feição genérica que frequentemente está ausente devido à esfoliação (DZP-17648b, Figura 4H).

\section{Outros exemplos}

Outro caso interessante é mostrado por um espécime de C. signifer, DZP-2234a (Figura 3C), proveniente do município de Ponta Grossa. Embora completo, parte de um dos lobos pleurais está faltando. $\mathrm{O}$ lobo faltante corresponderia à parte do corpo do trilobite mais exposta à ação do intemperismo, isso quando ainda incluído na matriz sedimentar. O fato deste exemplar estar estendido e com céfalo, tórax e pigídio preservados, mostra que o lobo pleural faltante não foi perdido durante a fase bioestratinômica, mas sim devido à exposição acentuada de parte de seu exoesqueleto ao intemperismo. Ou seja, a porção perdida estava voltada à face do afloramento, exposta à ação do clima e outras intempéries naturais.

\section{DISCUSSÃO}

Conforme indicado pelos exemplos aqui apresentados, alguns caracteres utilizados na diagnose de gêneros e espécies de calmoniídeos e homalonotídeos da Formação Ponta Grossa são suscetíveis a modificações tafonômicas. Em especial, as alterações produzidas pela compactação postmortem e a obliteração via intemperismo destacam-se como os principais fatores naturais que contribuem para modificar as feições morfológicas da carapaça dos trilobites estudados. Em alguns casos, as modificações morfológicas produzidas têm, ao que tudo indica, impacto na sistemática da fauna de calmoniídeos e homalonotídeos. Embora a proposição de sinonímias e a discussão sobre a validade taxonômica de espécies de calmoniídeos não faça parte do escopo do presente estudo, apontar possíveis incongruências no reconhecimento de certos táxons poderia constituir ponto de partida para uma investigação sobre a validade de algumas das espécies de trilobites do Devoniano paranaense.

Por exemplo, Calmonia signifer difere de C. subseciva somente pela presença de um espinho terminal no pigídio (Clarke, 1913). No entanto, em espécimes melhor preservados de C. subseciva, Clarke (1913) observou que pequenos processos espinhosos correspondentes em posição e número aos espínulos de $C$. signifer, podem estar presentes. Dessa forma, a hipótese de que $C$. subseciva corresponda a espécimes de $C$. signifer, não pode ser rejeitada, uma vez que C. subseciva pode ter sido estabelecida, provavelmente, a partir da descrição de espécimes esfoliados de $C$. signifier (Clarke, 1913:est.7, figs. 2-10).

Algumas das alterações tafonômicas observadas interferem também no status das espécies do gênero Paracalmonia (Figura 5). Popp et al. (1996) chamaram a atenção para a grande semelhança morfológica entre as espécies de $P$. cuspidata e $P$. paranaensis e para o precário estado de preservação dos espécimes disponíveis para estudo. Considerando as observações de Popp et al. (1996) e os resultados aqui obtidos, é possível enfatizar a necessidade urgente de revisão das espécies desse gênero. Por exemplo, P. paranaensis e P. cuspidata (Popp et al., 1996)
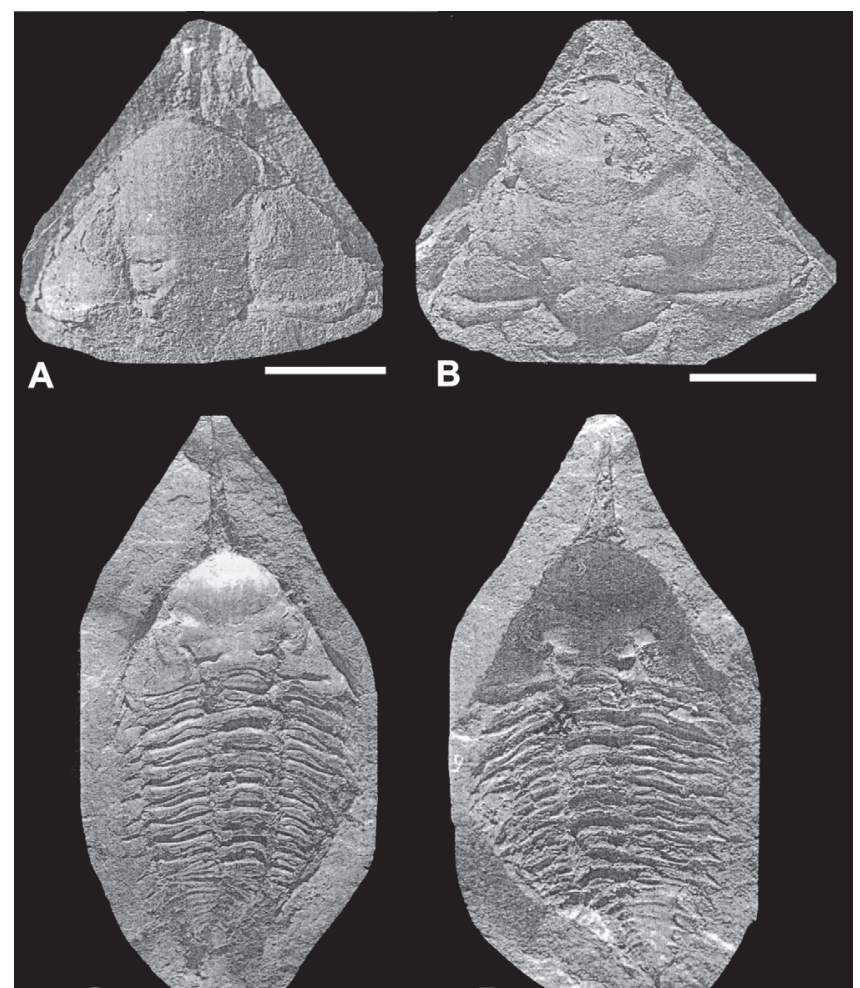

C

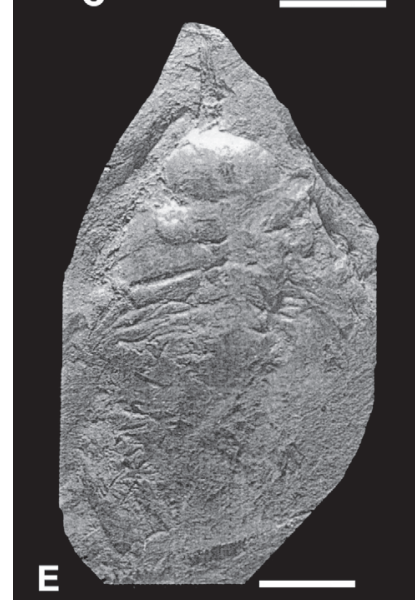

B

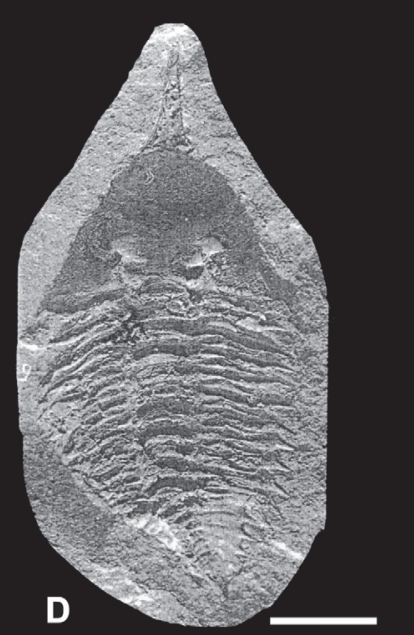

$\mathbf{F}$

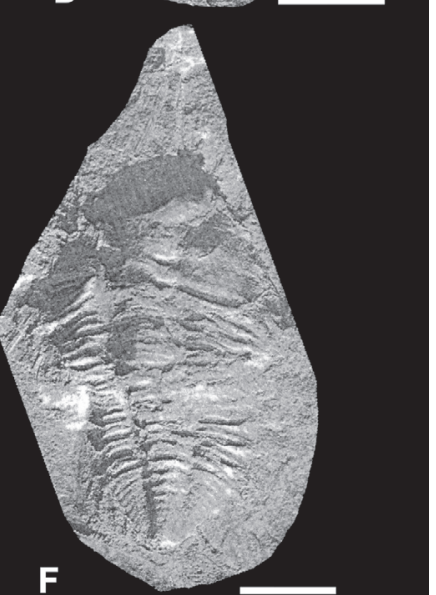

Figura 5. Paracalmonia cuspidata (A-B) e P. paranaensis (C-F): A-B, espécimes esfoliados e compactados, sulcos axiais L1, L2 fracamente marcados; C, exemplar não esfoliado, sem compactação, sulcos axiais L1, L2 bem marcados, lobo glabelar inflado; D, exemplar esfoliado; E-F, espécimes não esfoliados, sem compactação, sulcos axiais L1 e L2 bem marcados, lobo glabelar inflado (modificado de Popp et al., 1996). Escala em A = $4 \mathrm{~mm}, \mathbf{B}=$ $5,7 \mathrm{~mm}, \mathbf{C}-\mathbf{D}=6,6 \mathrm{~mm}, \mathrm{E}-\mathrm{F}=7,5 \mathrm{~mm}$

Figure 5. Paracalmonia cuspidata (A-B) and P. paranaensis (CF): A-B, exfoliated and flattened specimens, weakly marked axia furrows L1, L2; C, uncompressed and unexfoliated specimen, well marked axial furrows L1, L2, glabelar lobe inflated; D, exfoliated specimen; E-F, well preserved specimen, well defined axial furrows L1, L2, inflated glabelar lobe (modified from Popp et al., 1996). Scale bar in $\mathbf{A}=4 \mathrm{~mm}, \mathbf{B}=5.7 \mathrm{~mm}, \mathbf{C}-\mathbf{D}=6.6 \mathrm{~mm}, \mathbf{E}-\mathbf{F}=7.5 \mathrm{~mm}$. 
são ambas muito semelhantes quanto à morfologia, principalmente do tórax e do pigídio. Ao comparar espécimes esfoliados e compactados de P. cuspidata, bem como um exemplar não esfoliado e não compactado de $P$. paranaensis, fica visível que os sulcos axiais L1 e L2 do exemplar não esfoliado estão bem marcados (Figuras 5E, F), enquanto que no exemplar esfoliado estão fracamente representados (Figuras 5A, B). Adicionalmente, no exemplar compactado de $P$. cuspidata, o lobo glabelar não está inflado, quando comparado com o espécime de $P$. paranaensis, cujo lobo glabelar apresenta-se inflado (Figuras 5C, F). Notavelmente, a profundidade dos sulcos axiais L1 e L2 e a inflação do lobo glabelar são os únicos caracteres diagnósticos entre essas espécies, não apresentando outras características morfológicas que possam separá-las (Popp et al., 1996). De fato, os próprios autores destacam que o tórax e pigídio isolados de $P$. paranaensis geram confusão, por se assemelharem com os de outras espécies, o que levanta a possibilidade de que os espécimes atribuídos a essa espécie poderiam representar espécimes em bom estado de preservação de $P$. cuspidata (Popp et al., 1996:25).

Em Homalonotidae, Clarke (1913) menciona que espécimes de Burmeisteria herschelii variavam muito e irregularmente na sua condição tuberculada, sendo as formas jovens, em geral, as freqüentemente desprovidas de tais excrescências e que, essas aumentam em abundância com o tamanho e o desenvolvimento ontogenético dos homalonotídeos. Notavelmente, dentre o material estudado, o exemplar DZP2855 , com $1,34 \mathrm{~cm}$ de largura e $1,43 \mathrm{~cm}$ de comprimento (o menor exemplar de $B$. herschelii disponível para estudo), apresenta tubérculos no pigídio. Dessa forma, $B$. herschelii possui tubérculos em igual abundância, tanto nos exemplares maiores quanto nos menores, sendo que a ausência de tais estruturas provavelmente está relacionada à esfoliação da carapaça.

Finalmente, outro ponto a ser destacado é a diferenciação entre Digonus noticus e Burmeisteria herschelii. Uma das feições característica que separa essas espécies é a forma da glabela que, como colocado anteriormente, pode sofrer alterações de acordo com o grau de achatamento do espécime. Segundo Castro (1968), Cooper (1982) e Sandford (2005), o céfalo de $B$. herchelii, quando achatado, pode ser erroneamente atribuído a $D$. noticus, levando a interpretações sistemáticas equivocadas (Figura 4A, B).

\section{COMENTÁRIOS FINAIS}

A qualidade de preservação dos trilobites do Devoniano paranaense é variável, dependendo do litotipo considerado, da disposição das carapaças junto a matriz sedimentar, do grau de compactação e do intemperismo dos estratos portadores dos fósseis. Exemplares de uma mesma espécie ocorrendo em diferentes litotipos (arenitos versus argilitos) poderão mostrar um espectro bastante variável na qualidade de preservação. O mesmo não ocorrerá com as formas cuja distribuição estratigráfica está restrita a determinados litotipos e a condições diagenéticas similares. Obviamente, essas observações têm implicações na prática taxonômica, pois a descrição e a proposição de novas espécies devem, na medida do possível, considerar os efeitos dos processos de preservação na morfologia original de um determinado caráter ou conjunto de caracteres que podem ser diagnósticos.

\section{AGRADECIMENTOS}

O presente estudo contou com o indispensável auxílio e colaboração de M.J. Garcia (UnG), L.E. Anelli (IG/USP) e R.T. Bolzon (UFPR). A E. Bosetti (UEPG), um agradecimento especial, pelo auxílio nos trabalhos de campo em Ponta Grossa, PR, empréstimo de material para estudo, comentário sobre as versões iniciais do manuscrito e a indicação de literatura. Os autores gostariam de agradecer também a D.G. Cid (Universidad Autônoma de Madrid) pela leitura crítica do manuscrito e indicação de referências, bem como aos editores da RBP pelas sugestões que em muito enriqueceram o texto. Os autores agradecem ainda ao Departamento de Zoologia do IBB/UNESP, por facultar o uso de suas instalações, equipamentos e coleções. Suporte financeiro para esse projeto foi oferecido pela FAPESP (Proc. 05/00791-1).

\section{REFERÊNCIAS}

Arbizu, M. 1982. Trilobites Homalonotinae del Devónico de la Cordillera Cantábrica (NO de España). Trabajos de Geología, Universidad de Oviedo, 12:243-250.

Babcock, L.E. \& Speyer, S.E. 1987. Enrolled trilobites from the Aldean Pyrite Bed, Ledyard Shale (Middle Devonian) of western New York. Journal of Paleontology, 61:539-548.

Baldis, B.A.; Benedetto, L.; Blasco, G. \& Martel, M.E. 1976. Trilobites silúrico-devónicos de la Sierra de Zapla (Nordeste de Argentina). Ameghiniana, 23(3-4):185-203.

Bergamaschi, S. 1999. Análise estratigráfica do Siluro-Devoniano (Formação Furnas e Ponta Grossa) da sub-bacia de Apucarana, bacia do Paraná, Brasil. Programa de Pós-graduação em Geologia Sedimentar, Instituto de Geociências, Universidade de São Paulo São Paulo, Tese de Doutorado, 167 p.

Bergamaschi, S. \& Pereira, E. 2001. Caracterização de seqüências deposicionais de $3^{\mathrm{a}}$ ordem para o Siluro-Devoniano da subbacia Apucarana, bacia do Paraná, Brasil. In: J.H.G Melo \& G.J.S. Terra (eds.). Correlações de seqüências paleozóicas sulamericanas. Ciência Técnica Petróleo. Seção Exploração de Petróleo. 20:63-72.

Bosetti, E.P. 2004. Tafonomia de alta resolução das fácies de offshore da sucessão devoniana na região de Ponta Grossa, Paraná, Brasil. Programa de Pós-Graduação em Geociências, Universidade Federal do Rio Grande do Sul, Porto Alegre, Tese de Doutorado, $165 \mathrm{p}$.

Brett, C.E. \& Baird, G.C. 1986. Comparative taphonomy: A key for paleoenvironmental reconstruction. Palaios, 1:207-227.

Busch, R.M. \& Swartz, F.M. 1985. Molting and description of a new homalonotid trilobite from Pennsylvania. Journal of Paleontology, 59(5):1062-1074.

Carvalho, M.G.P. 2006. Devonian trilobites from the Falkland Islands. Palaeontology, 49(1):21-34.

Carvalho, M.G.P. \& Edgecombe, G.D. 1991. Lower-early middle Devonian calmoniid trilobites from Mato Grosso, Brazil, and related species from Paraná. American Museum Novitates, 
3022:1-13.

Carvalho, M.G.P.; Edgecombe, G.D. \& Lieberman, B.S. 1997. Devonian calmoniid trilobites from the Parnaíba Basin, Piauí State, Brazil. American Museum Novitates, 3192:1-11.

Carvalho, M.G.P. \& Quadros, L. P. 1987. Trilobitas devonianos do flanco noroeste da bacia do Paraná. In: CONGRESSO BRASILEIRO DE PALEONTOLOGIA, 10, 1987. Anais, Rio de Janeiro, 2:545-565.

Castro, J.S. 1968. Trilobitas da Formação Pimenteiras, Devoniano do Estado do Piauí. Anais da Academia Brasileira de Ciências, 40(4):481-489.

Chlupác, I. 1981. Homalonotid trilobites from the metamorphic Devonian of the Hrubý Jeseník Mts., Czechoslovakia. Casopis pro Mineralogii a Geologii, 26(4):361-370.

Clarke, J.M. 1913. Fósseis devonianos do Paraná. Monografia do Serviço Geológico e Mineralógico do Brasil, 1:1-353.

Cooper, M.R. 1982. A revision of the Devonian (Emsian-Eifelian) trilobita from the Bokkeveld Group of South Africa. Annals of the South African Museum, 89(1):1-174.

Cruz, G.C.F. 2007. Alguns aspectos do clima dos Campos Gerais. In: M.S. Mello; R.S. Moro \& G.B. Guimarães (eds.). Patrimônio natural dos Campos Gerais. Editora UEPG, Ponta Grossa, p. 59-72.

Edgecombe, G.D. 1990. Lectotype and synonymy of Cryphaeus nicholsi Roy, 1929 (Trilobita, Devonian). Journal of Paleontology, 64(6):1044.

Eldredge, N. \& Branisa, L. 1980. Calmoniid trilobites of the Lower Scaphiocoelia Zone of Bolivia, with remarks on related species. Bulletin of the Amewrican Museum of Natural History, 165(2):185-289.

Fernández Lopez, S.R. 2000. Temas de Tafonomía. Departamento de Paleontologia, Universidad Complutense de Madrid, 167 p.

Fortey, R.A. 1974. The Ordovician trilobites of Spitsbergen, Olenidae. Norsk Polarinstitutt Skrifter, 160:1-129.

Ghilardi, R.P. 2004. Tafonomia comparada e paleoecologia dos macroinvertebrados (ênfase em trilobites), da Formação Ponta Grossa (Devoniano, sub-bacia Apucarana), Estado do Paraná, Brasil. Programa de Pós-Graduação em Geologia Sedimentar, Instituto de Geociências, Universidade de São Paulo, São Paulo, Tese de Doutorado, 113 p.

Ghilardi, R.P. \& Simões, M.G. 2007. History and development of trilobite research in Brazil. In: D.G. Mikulic; E. Landing \& J. Kluessendorf(eds.). Fabulous fossils -300 years of worldwide research on trilobites. New York State Museum Bulletin, 507:97104.

Gill, E.D. 1948. Palaeozoology and taxonomy of some Australian homalonotid trilobites. Proceedings of the Royal Society of Victoria, 61:61-72.

Harrington, H.J.; Henningsmoen, G.; Howel, B.F.; Jaanusson, V.; Lochman-Balk, C.; Moore, R.C.; Poulsen, C.; Rasetti, F.; Richter, E.; Richter, R.; Schmidt, H.; Sdzuy, K.; Struve, W.; Størmer, L.; Stubblefield, C.J.; Tripp, R.; Weller, J.M. \& Whittington, H.B. 1959. Trilobita. In: R.C. Moore (ed.). Treatise on Invertebrate Paleontology Part O. Arthropoda, Geological Society of America and University of Kansas Press, p. O38-O526.

Henningsmoen, G. 1957. Los trilobites de las capas de Saukianda, Cámbrico Inferior, en Andalucía. Estudios Geológicos, 14(3536):251-255.

Henry, J.L. 1981. Quelques trilobites Homalonotidae et leur distribution dans l'Ordovicien du Massif Armoricain. Bulletin de la Societe Geologique de France, 7(4):345-351.
Hesselbo, S.P. 1987. The biostratinomy of Dikelocephalus sclerites: implications for the use of trilobite attitude data. Palaios, 2:605608.

Holz, M. \& Schultz, C.L. 1998. Taphonomy of the South Brazilian Middle Triassic paleoherpetofauna: Fossilization mode and implications for morphological studies. Lethaia, 31(4):335-348.

Holz, M. \& Simões M.G. 2002. Elementos fundamentais de Tafonomia. Editora da UFRGS, Porto Alegre, 240 p.

Hughes, N.C. 1993. Distribution, taphonomy and functional morphology of the Upper Cambrian trilobite Dikelocephatus. Milwaukee Public Museum Contributions in Biology and Geology, 84:1-49.

Hughes, N.C. 1995. Trilobite taphonomy and taxonomy: A problem and some implications. Palaios, 10:283-285.

Hunda, B.; Hughes, N.C. \& Flessa, K.W. 2006. Trilobite taphonomy and temporal resolution in the Mt. Orab Shale Bed (Upper Ordovician, Ohio, U.S.A.). Palaios, 21:28-45.

IAPAR - Instituto Agronômico do Paraná, 2000. Cartas climáticas do Estado do Paraná. Londrina, IAPAR, 1 CD-Rom. Versão 1.0 .

Jell, P.A. 1985. Tremadoc trilobites of the Digger Island Formation, Waratah Bay, Victoria. Memoirs of the Museum of Victoria, 46:53-88.

Kegel, W. \& Costa, M.T. 1951. Espécies neopaleozóicas do Brasil, da Família Aviculopectinidae, ornamentadas com costelas fasciculadas. Boletim do Departamento Nacional de Produção Mineral, Divisão de Geologia e Mineralogia, 137:1-48.

Kiaer, J. 1917. The Lower Cambrian Holmia fauna at Tomten in Norway. Norske Videnskaps Academi i Oslo Skrifter 1 Matematisk videnskalelig Klasse, 10:1-141.

Kozlowski, R. 1923. Faune Dévonienne de Bolivie. Annales de Paleontologie, 12(1/2):1-112.

Lake, P. 1904. The trilobites of the Bokkeveld Beds. Annals of the South African Museum, 4:1-4.

Lange, F.W. \& Petri, S. 1967. The Devonian of the Paraná Basin. In: J.J. Bigarella (ed.). Problems in Brazilian Devonian Geology. Boletim Paranaense de Geociências, 21-22:5-55.

Lieberman, B.S. 1993. Systematics and biogeography of the "Metacryphaeus group" Calmoniidae (Trilobita, Devonian), with comments on adaptive radiations and the geological history of the Malvinokaffric Realm. Journal of Paleontology, 67(4):549570 .

Lieberman, B.S.; Edgecombe, G.D. \& Eldredge, N. 1991. Systematics and biogeography of the "Malvinella Group", Calmoniidae (Trilobita, Devonian). Journal of Paleontology, 65(5):824-843.

Lucas, S. 2001. Taphotaxon. Lethaia, 34:30.

Mack, R. 2002. Geografia física do Estado do Paraná. $3^{\text {a }}$ ed., Imprensa Oficial, Curitiba, $440 \mathrm{p}$.

MacNaughton, R.B. \& Pickerill, R.K. 2003. Taphonomy and the taxonomy of trace fossils: A commentary. Lethaia, 36:66-70.

Myszynski, L.J. \& Bosetti, E. 2006. Corredor de afloramentos da sucessão devoniana (?Lockoviano-Frasniano) do bairro de Uvaras, Ponta Grossa, Paraná, Brasil. In: ENCONTRO ANUAL DE INICIAÇÃO CIENTÍFICA, 15, Ponta Grossa, UEPG, Resumos em meio digital, p. 1.

Petri, S. 1948. Contribuição ao estudo do Devoniano paranaense. Departamento Nacional de Produção Mineral, 125 p. (Boletim 129).

Petri, S. 2006. Problems in the utilization of the Brazilian Code of Stratigraphic Nomenclatures as related to modern researches. Revista Brasileira de Geociências, 36(1):203-208.

Pillet, J. 1961. Contribution à l'etude des homalonotidae (Trilobites) 
des Grés à Dalmanella monnieri (Siegénien infeérieur) du Massif Armoricain. Bulletin de la Societe Geologique de France, 3(5):457-462.

Popp, M.T.B. 1985. Revisão dos trilobitas calmoniideos e comunidades faunísticas da Formação Ponta Grossa, Devoniano, no Estado do Paraná. Programa de Pós-Graduação em Geociências, Universidade Federal do Rio Grande do Sul, Porto Alegre, Tese de Doutorado, $112 \mathrm{p}$.

Popp, M.T.B.; Coimbra, J.C. \& Hauch, A. 1996. Revisão do gênero Paracalmonia Struve, 1958 (Proboloides Clarke, 1913), Trilobita - um ensaio de sistemática filogenética. Gaia, 12:1932.

Reed, F.R.C. 1918. Notes on the genus Homalonotus. Geological Magazine, New Series, ser. VI, 5:262 - 327.

Reed, F.R.C. 1925. Revision of the fauna of the Bokkeveld Beds. Annals of the South African Museum, 22:165-232.

Reed, F.R.C. 1930. Uma nova fauna permocarbonífera do Brasil. Monografia do Serviço Geológico e Mineralógico, 10:1-45.

Rocha-Campos, A.C. 1966. Implicações em sistemática do tipo de preservação dos lamelibrânquios fósseis de Taió, SC. Boletim da Sociedade Brasileira de Geologia, 15(1):5-13.

Rocha-Campos, A.C. 1970. Moluscos permianos da Formação Rio Bonito (Subgrupo Guatá), SC. Boletim do Departamento Nacional de Produção Mineral, Divisão de Geologia e Mineralogia, 251:1-89.

Rodrigues, S.C.; Leme, J.M. \& Simões, M.G. 2003. Tafonomia comparada dos Conulatae (Cnidaria), Formação Ponta Grossa (Devoniano), bacia do Paraná, Estado do Paraná. Revista Brasileira de Geociências, 4(33):1-10.

Sandford, A.C. 2005. Homalonotid trilobites from the Silurian and Lower Devonian of south-eastern Australia and New Zealand (Arthropoda: Trilobita: Homalonotidae). Memoirs of Museum Victoria, 62(1):1-66.

Saul, J. 1965 Trilobita. In: G.A. Doumani; R.S. Boardman; A.J. Rowell; A.J. Boucot; J.G. Johnson; A.L. Mcalester; J. Saul; D.W. Fisher \& R.S. Miles (eds.). Lower Devonian fauna of the Horlick Formation, Ohio Range, Antarctica. Antarctic Research Series, 6:241-281.

Saul, J.M. 1967. Burmeisteria (Digonus) accraensis, a new homalonotid trilobite from the Devonian of Ghana. Journal of Paleontology, 41(5):1126-1136.
Simões, M.G.; Ghilardi, R.P.; Sales, A.M.F.; Rodrigues, S.C.; Leme, J.M. \& Mello, L.H.C. 2000a. Taphonomy and genesis of the "Conularia Beds" from Ponta Grossa Formation (Devonian) within a sequence stratigraphy framework. In: PALEO 2000/ SP, Botucatu, Boletim de Resumos, p. 20.

Simões, M.G.; Mello, L.H.C.; Rodrigues, S.C.; Leme, J.M. \& Marques, A.C. 2000b. Conulariid taphonomy as a tool in paleoenvironmental analysis. Revista Brasileira de Geociências, 4(30): 757 - 762

Simões, M.G.; Leme, J.M.; Rodrigues, S.C. \& Van Iten, H. 2003. Some Middle Paleozoic conulariids (Cnidaria) as possible example of taphonomic artifacts. Journal of Taphonomy, 1(3):165-186.

Soares, S.P. 2007. Sistemática, tafonomia e paleoecologia de Trilobita, Phacopida (Homalonotidae e Calmoniidae), Formação Ponta Grossa (Devoniano), sub-bacia Apucarana, Estado do Paraná, Brasil. Programa de Pós-Graduação em Geologia Sedimentar, Instituto de Geociências, Universidade de São Paulo, São Paulo, Dissertação de Mestrado, 140 p.

Speyer, S.E., 1987. Comparative taphonomy and palaeoecology of trilobite lagerstätten. Alcheringa, 11:205-232.

Speyer, S.E. 1988. Bioestratinomy and functional morphology of enrollment in two Middle Devonian trilobites. Lethaia, 21:121138.

Speyer, S.E. \& Brett, C.E. 1985. Clustered trilobite assemblages in the Middle Devonian Hamilton Group. Lethaia, 18:85-103.

Speyer, S.E. \& Brett, C.E. 1986. Trilobite taphonomy and Middle Devonian taphofacies. Palaios, 1(3):312-327.

Taylor, M.E. 1978. Type species of the Late Cambrian trilobite Eurekia Walcott, 1916. Journal of Paleontology, 52:1054-1064.

Thomas, A.T. 1977. Classification and phylogheny of Homalonotid trilobites. Palaeontology, 20(1):159-178.

Tomczykowa, E. 1975. The Trilobite Subfamily Homalonotinae from the Upper Silurian and Lower Devonian of Poland. Acta Palaeontologica Polonica, 20(1):3-46.

Wenndorf, B.K.W. 1990. Homalonotinae (Trilobita) aus dem Rheinischen Unter-Devon. Palaeontographica Abt. A, 211:1184.

Westrop, S.R. 1986. Taphonomic versus ecologic controls on taxonomic relative abundance in tempestites. Lethaia, 19:123132.

Zabini, C. 2007. Lingulideos da sucessão devoniana da bacia do Paraná, região dos Campos Gerais, Brasil: revisão de conceitos biológicos-ecológicos e análise tafonômica básica. Programa de Pós-Graduação em Geociências, Universidade Federal do Rio Grande do Sul, Porto Alegre, Dissertação de Mestrado, $130 \mathrm{p}$.

Received in November, 2007; accepted in March, 2008. 